\title{
TEACHING PRACTICAL RESEARCH FOR SENIOR HIGH SCHOOL AN IN-DEPTH STUDY
}

\author{
$1^{\text {st }}$ Marlyn D. Lucas \\ Teacher \\ National High School \\ CAR, Philippines \\ mdlucas@dotclsu.edu.ph
}

\author{
$2^{\text {nd }}$ Hernando L. Bernal Jr. \\ Professor \\ FEU-NRMF \\ NCR, Philippines \\ bhambernal@gmail.com
}

\author{
$3^{\text {rd }}$ Mark P. Lucas \\ Teacher \\ Philippine Science High School \\ Ilocos Sur, Philippines \\ markmaclucas@gmail.com
}

https://doi.org/10.48161/qaj.v1n2a61

\begin{abstract}
Teaching Practical Research in the Senior High School was a challenge but at the same time a room for exploration. This study investigated the key areas in the interconnected teaching strategies employed to grade 12 students of which are most and least helpful in coming up with a good research output and what suggestions can be given to improve areas that are least useful. It is qualitative in nature and used phenomenological design. Reflection worksheets and interview schedule were the main sources of data.
\end{abstract}

Results reveal that students come up with a good research output because of the following key areas: 'guidance from someone who is passionate with research' as represented by their research critique, research teacher, resource speaker from the seminar conducted, and group mates; 'guidance from something or activities conducted' like the sample researches in the library visitation, worksheets answered, and the research defenses; and 'teamwork' among the members of the group. On the other hand, key areas which are least useful are: 'clash of ideas and unequal effort' among the members; 'time consuming for some of the written works'; and 'no review of related literature' during the library hopping. Suggestions given where: to choose your own group mates of which each member should have the same field of interest, to remove worksheets not needed in the research paper; and to check online regarding availability of literature in the library. Further suggestions are to rearranged the sequence of the interconnected strategies which are as follows: grouping of students, having a research critique, seminar in conducting research, library visitation/work activity, proposal defense, final defense and the worksheet activities be given throughout the semester. Furthermore, there should be a culminating activity for students to share their outputs.

Teaching research is a wholesome process. By then, the researcher recommends to organize a group orientation for the teacher-coaches/mentors on the creation of school research council or school mentoring committee for peer reviewing on the students research output. Further, student research presentation (oral, poster, gallery type, etc.), student research conference/colloquium, student research journal, etc. be organized to further nourish the culture of research in the part of the students, teachers and staffs involve.
Keywords-practical research subject, interconnected teaching strategies, research critique, worksheets, library visitation, seminar, defense, group work

\section{INTRODUCTION}

$\mathrm{K}$ to 12 Curriculum covers 13 years of basic education in the Philippines of its last two years is the Senior High School level where it is already in its full swing implementation. As informed by the Department of Education, Senior High School level will equip the learners with skills that will better prepare them for the future. In preparing the learners for the future there are subjects that they have to take regardless of what track and strand they choose. Part of the subjects they have to take is Practical Research 1 (Qualitative Research) and Practical Research 2 (Quantitative Research) where they will be equipped with the ways and how's of doing a research and in the end, coming up with a research output.

Practical Research 1 is now being taught to the Grade 11 students of nationwide and for the teachers who were given the task to teach this is a challenge and in one way or another a room for exploration. Both teaching and research help you develop insight into your field, refine your communication skills, and draw on your ability to select and organize content in a meaningful way [1]. Therefore, the researcher thought of investigating what would be the most useful strategies in teaching Practical Research 1 for the researcher to develop an insight which is useful in the field and be able to come up with a meaningful teaching and learning process for the subject.

Teaching Research subject as the researcher believes is not an easy task for every teacher who is assigned to teach it. Research subject has been regarded as a heavy task and difficult one since you really need time and effort to come up with a research output. There are a lot of things we have to consider in teaching Practical Research 1 in Senior High School where one of which is an endless revision on both ends considering the fact of the number of researches you set in your class [2]. Moreover, teaching 
the subject Practical Research 1 is an exploratory part for the teachers. This is a subject which needs a teacher who has background in the field of research, who has expertise in any area for technicalities and who is willing to explore strategies that can help students embrace the culture of research since todays $\mathrm{K}$ to 12 Curriculum is geared towards students to be skilled in research. Further, Chamberlain [3] mentioned experiential approach in learning to do research where this approach is more advantageous and valuable since it promotes application and generalization of the skills and knowledge gained. Practically speaking, students should do a research and come up with an output in their Practical Research subjects for them to experience and own the skill of doing research which is an expected skill for them in the tertiary level. Given this challenging task, what can be the strategies that the researcher can use for students to learn and embrace research and to come up with a research output that has a sense of purpose and which is publishable. As the researcher believes, research outputs are useless if they are not meant to be shared or be published.

Therefore, the main reason for conducting the study is to analyze the interconnected teaching strategies that can help teachers teach the subject Practical Research 1 and to come up with a research output of the students. The results of the study can be used by teachers in the Senior High School teaching Practical Research 1 in planning for the appropriate teaching strategies and in coming up with a research output systematically planned with a sense of purpose.

Thus, this study will investigate the key areas in the interconnected strategies employed to grade 12 students that the students find most useful in coming up with a good research output. Likewise, the least useful strategy and on what suggestions can be given to improve areas that are least useful.

This study aimed to investigate the effectiveness of interconnected strategies applied to Grade 12 students in learning the subject Practical Research 1. Specifically, it will seek to answer the following questions:

1. What key areas in the interconnected strategies do students find most useful in coming up with a good research output? Why?

2. What key areas in the interconnected strategies do students find least useful?

3. What suggestions can be given to improve areas that are least useful?

\section{METHOD}

The study is qualitative in nature. It had used of phenomenology as its research design since the focus of the study is to investigate the key areas in the interconnected teaching strategies employed to grade 12 students of which they find most useful or least useful in coming up with a good research output. And at the same time, on what suggestions can be given to improve areas that are least useful.

\section{A. Participants and/or other Sources of Data and Information}

The participants of the study are the Grade 12 students of a local national high school who are enrolled in Practical Research 1 subject. Series of reflections had been given to each student after applying the strategies in learning the subject. After which, an interview schedule was conducted to selected students. This reflection from the students and transcribed interviews has been the main sources of data and information for the study.

\section{B. Data Gathering Methods}

Data for the study was gathered every after strategy was employed. Worksheet reflections were given for the students to reflect on if the strategy was of help for them in learning and coming up with a good research output. After which, an interview schedule was conducted to selected students in determining further the effectiveness of the strategies employed.

\section{Data Analysis Plan}

The study had made use of phenomenological reduction through repertory grid in analyzing the data coming up with themes from the reflections of the students in each teaching strategies employed. Then, interview schedule had been conducted to selected students in determining further the effectiveness of the strategies employed. From the transcribed information during the interview, cool and warm analysis had been used.

\section{Ethical Issues}

Letter of consent had been given to the students prior conducting the study assuring that the data collected will be used solely for the study and will be treated with utmost confidentiality. Further, if given the chance that this study be published, it should be used for academic purposes only.

\section{RESULT AND DISCUSSION}

The interconnected strategies employed for this study in teaching Practical Research 1 were an endeavor that had really turned into an accomplishment in the part of the teacher and the students. The following themes show how students were able to learn how to do research and to come up with a good research output.

\section{Key Areas which are Most Useful in the Interconnected Teaching Strategies}

\section{Guidance from someone who is passionate with research.}

Doing research without guidance from someone expert in the field is like doing something without an end goal. The role of the research critiques, the research teacher, the resource speaker from the seminar conducted and the 
group mates has had a big impact in the learning of students in doing and crafting their research output.

From the interview, it was obvious that students' most useful strategy was having a research critique in their chosen research topic. Research critiques with the research teacher and resource speakers served as mentors to the students, which played a big role in the students learning in doing and crafting their research output. As students say "research critiques has guide them all throughout the conduct of their chosen research study". They were guided by their research critique, research teacher and resource speakers in a way that their errors are being corrected, ideas and additional inputs in the conduct of the research is given, experience in conducting research is shared, encouragement and appreciation towards the research work is provided, and direction of the research work is seen and being checked. The result suggested that having mentor/s improved the students' motivation in doing the research which in turn improved academic learning. This proved the study of Hughes, et. al. [4] which states that mentoring improved academic learning. As their research teacher, it was a good and great strategy but thinking further, it is an additional task for the research critiques that needs to be addressed for the chosen critiques to enjoy and feel the process of doing so.

The resource speaker from the seminar conducted had further helped the students see the process of conducting a research. Information's and background of conducting research was shared by the speaker that were very useful for it has been the one used by the students and had been a motivation for them to learn the ways of conducting a research. Further, students had a clearer view of how they will conduct their research for they can easily ask suggestions from the speaker regarding their research. Furthermore, from the worksheet reflections of the students, the seminar conducted by the resource speaker was a big help as a starting researcher and an inspiration to finish the research output. This was so because the resource speaker has lightened up their minds and had inspired them in doing their research output. One student had noted that "the speakers' aura had really inspired us on the things to do in conducting a research". This scenario proved that learning and learning motivation of students were improved, Fejes, et. al [5].

Another factor that had guide students in coming up with a research output is the members of the group. From the interview conducted and the reflection worksheets, when members of the group involve themselves in the conduct of their research that indicates that they are interested and inspired to finish the given task. There is communication and initiative that voluntarily happens between and among the group which inspires each member to finish the task given for their research. Or otherwise that member becomes the "agin-agin nga groupmate" as written by a student in her reflection worksheet.

From the answers of the students, it implies that guidance from someone expert in the field plays a big role in learning the process of doing research. Students were able to come up with their research outputs because they were guided carefully by their research critiques as well as their research teacher. They had grasp ideas of doing research from the resource speaker during the seminar. And their group members had further inspired them to finish the task.

Guidance from something or activities conducted with regards to doing/conducting a research

The interconnected teaching strategies are series of activities conducted towards a research output of students. Sample researches seen in the library visitation/work activity, the worksheets answered throughout the semester, the research proposal defense, seminar in conducting research, and the final research defense are the activities that had guided more the students in the process of crafting and doing their research output.

Library visitation/work activity had helped the students most in the review of related literatures of their own research focus. "We were given additional idea and guidance as to how will we conduct our research because of the availability of research studies (thesis, dissertations and journals), and locally reviewed literatures that you cannot find in the internet" as said during the interview. Students also had a comparison as to their research focus if it has a sense or not. Further from the reflection worksheet of the students, it points out that they had experienced a true library work. This was perhaps of the given worksheet for them to answer as a group during the activity. Though other groups were not able to find references for their research focuses, still, they had enjoyed the activity and done their best for the review of related literatures for their research focus.

Worksheet activities were given all throughout the semester. As informed by the students during the interview, worksheet activities were a way for them to organize the data they need in their research output. It was also a moment for them to have their brainstorming for their research focus. 'It was by process that parts of the research are divided' that reminds them also of the things they have to do for their research output. These answers were also seconded by the reflections of the students. From the reflection worksheet, worksheet activities was 'a way to be knowledgeable with research focus', 'a guide that had been their basis in crafting their research papers (the introduction, literatures, research questions, methodology and results and discussions), and it had improve their skills in doing research where one student says, 'it had developed her intellectual abilities in doing research' while other student says, 'they were able to be more responsible and be more motivated to work harder and to do better'.

The research proposal defense was an activity designed for students to share their research proposal. From the interview, students had said that it has been a way for them to be corrected and directed towards what they really would like to research on. Recommendations 
or additional inputs are being shared by the research critique and the research teacher that had guide them more towards coming up with a research output. It was the moment of sharing and suggesting things towards improvement of how the research is to be conducted or whether to pursue or not the research focus. This was also the moment where other members of the group are being aware of what there group would like to research on. Further from the reflection worksheet, the research proposal defense was: a way to correct mistakes in conducting research and students had gained selfconfidence. It was an activity that had helped them improve more their proposal for a more reliable and good research output and it was an opportunity to gain their self-confidence through trusting their self that they can stand and defend their research focus, to speak out and say what's in their mind, and to trust their group mates that they can all defend their research focus.

With the seminar in conducting research, it was mentioned earlier that it had helped and guided more the students see the process of conducting a research which was also affirmed by the reflection worksheets of the students' stating that this activity has guided them more towards collecting and analyzing their chosen research focuses.

The last activity which guided more the students in doing and crafting their research output was the final research defense. Final research defense was the last strategy employed and for the students it was their way to share their master piece (their research output). From the interview, students' see this as a final judgement for they would know if their research is of quality and reliable from their panels. In the reflection worksheet, it had intrinsically helped them boost their self-confidence and to take courage to present their paper to the panels. In doing so, they had to initiatively help finish their research paper and be knowledgeable about it.

As recommended by Jenkins, A. et.al. [6] in their study, effective management of research by individuals, departments, institutions and funding bodies is a way to resolved the many of perceived disadvantages in doing research. Activities conducted with regards to doing/conducting a research to students had been managed effectively that had led the students to come up with their research output. Further, from the concept of Activity Theory as mentioned by Kuutti, K. [7] in his study states that: "Activity Theory claims that activities cannot be really understood without seriously analyzing the historical development which has led to their present state. The activities themselves and their elements are under continuous development, and this development is not linear or straight forward but uneven and continuous". This just implies that the interconnected activities employed to students the whole semester was effective that it had guided the students further in crafting and making their research output because the key ideas in an Activity Theory was accomplished. These key areas were: a. activities as basic units of analysis, b. historical development of activities, and c. internal mediation within activities.

\section{Teamwork}

"Two heads is better than one". Two of the participants had said this during the interview. Teamwork is another key to come up with a good research output and this was evident in the strategies: group work research, research defenses and filling up worksheet activities. As mentioned by Rousseau et al. [8], working in teams increases productivity, innovation and team members' satisfaction.

In the group research, there is sharing of insights and ideas for a more fruitful research output, there is division of work, effort and financial matters, and there is teamwork which all helps beat the deadlines and saves time. Further, as said by one of the students "mas masaya kapag may kasama". This was also seconded by the reflection worksheet where with teamwork (working together as a team) helps finish the research paper on time, gain knowledge in doing research, and be more responsible in doing research. Some says, it gives joy to their hearts more in so if every member of the group worked together. The result proved the Rousseau et al. [9] result that team members must work together to achieve the teams purpose.

Teamwork was also very evident in the two defenses (the research proposal defense and the final research defense). It was during these strategies that each member of the group extended their involvement towards crafting and finalizing their research outputs. During these activities, almost all took the courage to defend their outputs aiming a good presentation that in the end some say they want to do more research and to love research. This scenario showed that students' were intact in their groupings which proved a study that intact teams were more effective than non- intact teams, McEwan, et. al. [10].

Further, teamwork was intensified during the worksheet activities throughout the semester. There were individual worksheets but there are also group work worksheets. These group work worksheets helped the students brainstorm towards each part of their research output. To think and share their ideas within the group towards their chosen research focuses that they may be able to answer the questions presented.

The researcher as their research teacher would not hesitate to apply these interconnected strategies again because the researcher knows that the research skill should be owned and mastered by the senior high students before they graduate high school. The research skill should already be innate to them because it is one of the needs in the tertiary level and most especially in the real life scenario. These interconnected teaching strategies has been the key for them to learn, to do, to craft, to conduct and to come up with a research output which was a good research outputs. 
Key Areas which are Least Useful in the Interconnected Teaching Strategies

\section{Clash of ideas and unequal effort}

Clash of ideas and unequal effort was evident in the group work research strategy as informed by the participants during the interview. Reasons behind were: there is a chaos of ideas (clash of ideas) that at times no one gives in, only one works unless other members are "on the job/on the go" in the research, not all are doing their part, and some believes that 'you can do your research as long as you are willing to finish it'. In other words, when a group does not click, that is, each member has different philosophies in life, then, there is no collaboration that affects the fulfilment of a certain task.

\section{Time consuming for written works}

Some of the worksheets answered are not needed that it consumes time. As said during the interview by one of the participant, "it's hard to compress ideas and it's always the same thing being written". Although some participants say, this was one way to check if each members of the group helped in the conduct of the research.

\section{No review of related literatures}

Some research focus of the students were very unique that during the library visitation/work activity, they were hard up finding review of related literatures related to their research focus and some end up not finding one.

\section{Suggestions Given to Improve Areas that are Least Useful in the Interconnected Teaching Strategies}

\section{Choose your own group mates}

Because of clash of ideas and unequal effort seen during the group work activities from some of the groupings, students had suggested that they should be the one to choose their own group mates. To choose their own group mates according to their field of interest because they believe that teamwork happens when your team mates are related with each other. Further, one participant intensifies that there should be cooperation and teamwork for the group and to have a thinking that what they are doing is also for their own sake. Or otherwise, "you do your research individually to have your own "obra maestra" one participant informs.

\section{Lessen worksheet activities}

Some of the worksheets not needed in doing and crafting a research output should be remove. This pertains to the reflection worksheets which one participant informs that 'reflections should be given after the research is over'. Further, other students suggested the following: put a worksheet in the concept of gathering literatures; it is better to be individual worksheet for other members to be motivated, lessen the blank parts in the worksheets and worksheet reflections regarding group members should also be included. Although, one participant informed that worksheets helped them recall things like the references.

\section{Check online}

One of the important parts of the research paper is the review of related literature that directs further the students of their chosen research topics. At times, there are a lot of literatures or the other way around there is few literatures or the worst no related literatures found. So, to address the issue, check the online first as said by one participant before going to the target library hopping. Big libraries have OPAC (Online Public Access Catalogue) where you can see list of literatures related to your research topics. Or set a date for online research reference searching as informed by one participant during the interview.

\section{Order of strategies}

A further suggestion of participants during the interview was the order of strategies. Following are the suggestions: seminar should be conducted first before gathering of data, prioritize the research critique because it's more ok to start doing a research when it is already checked, seminar first before library visitation; group work then seminar for more direction in what really will the group will focus on in their research, seminar should be conducted first so that right from the start you already know what to do. As a reflection, the researcher suggest the following sequence of the interconnected teaching strategies: a) grouping of students, b) having a research critique, c) seminar in conducting a research, d) library visitation/work activity, e) research proposal defense, f) final research defense. Worksheet activities will be given all throughout the semester.

\section{Culminating activities}

One participant had emphasized on a culminating activity to be conducted after having a research output. This activity should be a way for the students to share their master piece or "obra maestra" as they say. It is a way to address issues concern in that particular research focus. As the researcher believes, "researches are useless if they are not meant to be shared or be published".

\section{CONCLUSIONS AND RECOMMENDATIONS}

Teaching Practical Research in the Senior High School was a challenge but at the same time an area of exploration. The seven interconnected teaching strategies proposed by the researcher was indeed very helpful that students had learned the process of crafting and conducting a research and coming up with a good research output. As mentioned earlier, it was an endeavor that had turned into an accomplishment in the part of the teacher and the students.

The following are the conclusions:

1. Key areas in the interconnected strategies that students find most useful in coming up with a good research output are 'guidance from someone who is passionate with 
research' which is represented by the research critiques, research teacher, resource speaker from the seminar and group mates; 'guidance from something or activities conducted with regards to doing/conducting a research' which are the sample researches found during the library visitation/work activity, worksheets answered, research proposal defense and final research defense; and 'teamwork among the group mates' as shown through the group work research, filling up worksheets, research proposal defense and final research defense.

2. Key areas in the interconnected strategies that students find least useful in coming up with a good research output are 'clash of ideas and unequal effort' which is evident in the group work research; 'time consuming for written work' as noticed by some of the students in the filling up worksheet activities; and 'no review of related literature' as experienced by other groups during their collection of literatures.

3. Suggestions given to improve the least areas which are least useful are: students should choose their own group mates of which each member should have the same field of interest, to remove worksheet activities not needed in the research paper, and to check online regarding availability of literatures in the library. Further, sequence of the interconnected strategies should be a) grouping of students, b) having a research critique, c) seminar in conducting a research, d) library visitation/work activity, e) research proposal defense, f) final research defense, and e)worksheet activities is be given all throughout the semester. Furthermore, there should be a culminating activity for students to share their outputs.

The following are the recommendations:

1. Creation of school research council or school advisory committee for peer- review on the students research output.

2. Student research presentation (oral, poster, gallery type, etc.), student research conference/colloquium, student research journal, etc. should be organized by research teachers teaching Practical research subjects in partnership with the school research coordinators and the head of office in charge of research in the division to further nourish the culture of research in the part of the students, teachers and staffs involve.

3. Compilations of students' research output for others students' future references.

4. Another research be conducted to further quantify results presented.

\section{REFERENCES}

[1] Stanford University Teaching Commons Newsletter, "Combining Teaching and Research", 2017.

[2] Javier, C. M., "Key Takeaways in Senior High School's Practical Research 1", 2017.

[3] Chamberlain, K., "Teaching the practical research course", Sage Journals, vol. 13, issue 4, pp. 204-208, 1986.

[4] Hughes, C. et. al., "An Innovative University-Based Mentoring Program: Affecting College Students' Attitude and Engagement", Michigan Journal of Community Service Learning, vol. 16, pp. 69-78, 2009.

[5] Fejes, J. et. al., "The Model of Motivation Student Mentoring Program", 2014.

[6] Jenkins, A. et.al., "Teaching and Research: Student perspectives and policy implications", Studies in Higher Education, vol. 23, 2006 .

[7] Kuutti, K., "The Concept of Activity as a Basic Unit of Analysis for CSCW Research", Second European Conference on Computer-Supported Cooperative Work, 1991.

[8] Rousseau, V. et al., "Teamwork Behaviors A Review and an Integration of Frameworks", Small Group Research, vol. 37, pp. 540-570, 2006

[9] Rousseau, V. et al., "Teamwork Behaviors A Review and an Integration of Frameworks", Small Group Research, vol. 37, pp. 540-570, 2006.

[10] McEwan, D. et. al., "The Effectiveness of Teamwork Training on Teamwork Behavior and Team Performance: A Systematic Review and Meta-Analysis of Controlled Interventions", PLoS ONE, 2017 